\title{
USE OF NEURO-FUZZY LOGIC IN TOOL SELECTION AND COST ESTIMATION IN CNC Manufacturing of Prototypes
}

\author{
ChIANG, L.; FANTOZZI, C.; GRANCHI, M. \& VeTTORI, E.
}

Abstract: Neuro Fuzzy Logic can be used in the process of selecting the most appropriate tools as well as in Cost Estimation of CNC manufacturing of prototypes, which consists usually in a very small production series, many times as little as a single production unit. In such cases the cutting tools and manufacturing cost must be estimated in a reasonable amount of time and with a certain degree of accuracy, so the shop specialized in this market can be efficient and economically competitive. Therefore an Artificial Intelligence approach can be helpful. Our solution is implemented within an object-oriented programming paradigm for part description and data processing. A set of Fuzzy Logic Rules is applied in a decision-making process to obtain the best tool selection. We use Neural-Networks to generate selforganizing maps (SOM) for adjustment of either the shape and/or boundaries of the membership functions. The optimal cutting conditions are selected by a heuristic approach. Thus the time and cost of a competitive manufacturing job can be adequately predicted.

Key words: CNC Manufacturing, Cost, Neuro-Fuzzy, Cutting Tools
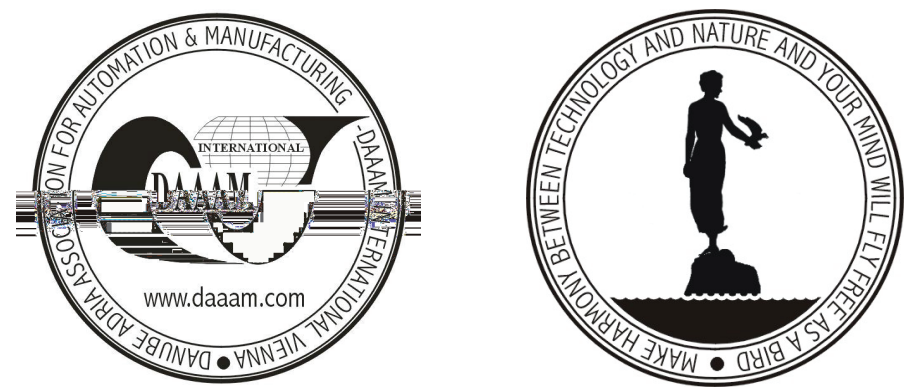

Authors' data: Ph. D. Chiang L.[uciano]*, Ass. Prof. Fantozzi C.[laudio]**, Ass, Prof. Granchi M[assimo]**, Ass. Prof. Vettori E[nrico]**, *Pontificia Universidad Católica de Chile, Santiago, Chile, **University of Pisa, Pisa, Italia, lchiang@ing.puc.cl, c.fantozzi@ing.unipi.it,_mgranchi@ing.unipi.it, e.vettori@ing.unipi.it

This Publication has to be referred as: Chiang, L.; Fantozzi, C.; Granchi, M. \& Vettori, E. (2006). Use of Neuro-Fuzzy Logic in Tool Selection and Cost Estimation in CNC Manufacturing of Prototypes, Chapter 13 in DAAAM International Scientific Book 2006, B. Katalinic (Ed.), Published by DAAAM International, ISBN 3-90150947-X, ISSN 1726-9687, Vienna, Austria

DOI: $10.2507 /$ daaam.scibook.2006.13 